\title{
THE IMPACT OF TRAFFIC FLOW STRUCTURE ON TRAFFIC SAFETY: THE CASE OF SLOVENIAN MOTORWAYS
}

\author{
Marina Zanne ${ }^{1}$, Aleš Groznik ${ }^{2}$ \\ ${ }^{1}$ Faculty of Maritime Studies and Transport, University of Ljubljana, Slovenia \\ ${ }^{2}$ Faculty of Economics, University of Ljubljana, Slovenia \\ Submitted 8 September 2014; resubmitted 16 March 2015; accepted 18 March 2015; \\ published online 29 March 2016
}

\begin{abstract}
Road traffic accident is an accident on a public road in which at least one moving vehicle has been involved and material damage or injury or death has occurred. Traffic accidents occur for various reasons, with one of them being the transport infrastructure and next the condition of traffic environment. Motorways are considered to be the safest roads, which have initially been planned as dedicated roads intended to be travelled only by personal cars, but the evolution of modal split of freight transport in Europe is causing the heterogeneity of traffic flows on these roads, which consequently affects the traffic safety. The aim of this paper is to explore the effects of changing volume and structure of traffic flows on road safety on Slovenian motorways. After the exhaustive analysis of past data, the paper provides different models for forecasting traffic safety on Slovenian motorways.
\end{abstract}

Keywords: motorways; traffic flow; traffic flows structure; traffic safety; road accident; accident rate; safety performance function (SPF); ARIMA model.

\section{Introduction}

Transport has played an important role in the economic development, but also in the evolution of society to the point where we are today (Cowie 2009); however, the uncontrolled growth of road transport has begun to show consequences, as transport problems have become more widespread and severe than ever in both industrialized and developing countries alike (Ortúzar, Willumsen 2011).

One of the basic qualities describing the functioning of transport system is traffic safety. Traffic safety is commonly measured in terms of number of accidents and severity of their consequences. There is no exact statistics showing the total number of people killed or injured in road accidents in the world; however, the estimation of the World Health Organization is that approximately 1.24 million people die every year on the world's roads, and another 20 to 50 million sustain nonfatal injuries as a result of road traffic crashes (WHO 2013) and there were almost 28,000 fatalities and 250,000 severely injured on European roads in 2012 alone (EC 2013). Furthermore, road traffic injuries are currently estimated to be the eighth leading cause of death globally (WHO 2013). Apart from the human suffering caused by these injuries, the socio-economic costs incurred are estimated at around 2\% of annual EU GDP (EC 2013a, 2013b).

Countries tackle the issue of road traffic safety in different ways, usually depending on the transport demand, development of transport system and financial resources, but the fact is that the availability of road infrastructure deeply influences the road safety. By theory motorways are considered to be the safest roads (ETSC 2008), but at the same time they are perceived to be the most monotonous for drivers. Motorways are designed to carry heavy traffic at high speed with the lowest possible number of accidents. They are designed to collect long-distance traffic from other roads, so that conflicts between long-distance and local traffic are avoided (Elvik et al. 2009).

The Slovenian motorways system is being constructed since 1970s. Slovenian government gave the priority to the construction of motorways network in the early 1990s when Slovenia became a sovereign state, given the fact that some segments of Slovenian motorway were already constructed, and considering the broader social and economic importance of motorways in regards to the railways. Today the Slovenian motor- 
ways system is pretty much completed while the railways remained in poor condition.

Having in mind that Slovenia is located on the important European transport routes, and that Slovenian legislation demands the use of higher-level roads for Heavy Goods Vehicles (HGVs) if they exist parallel to lower category roads, we decided to examine the traffic safety on Slovenian motorways, with the focus on the involvement of HGVs in the accidents. For this reason, we prepared a database covering information on traffic accidents and traffic flows on the Slovenian motorways for the period from 2001 to 2012, while the year 2013 served as a test year.

\section{Literature Overview}

Traffic flow theory seeks to describe in a mathematical way the interactions between the vehicles and their operators as well as the infrastructure. In traffic flow theory the first differentiation is made between microscopic and macroscopic traffic flow variables. Microscopic traffic flow variables focus on individual drivers, while macroscopic traffic flow variables reflect the average state of the traffic flow - Table 1 (see e.g. May 1990; Papageorgiou 2003; Dadić, Kos 2007; Hoogendoorn, Knoop 2013). A relation needs to be established between the microscopic behaviour and the macro performance of the flow (Lasmini et al. 2013).

Table 1. Framework for fundamental characteristics of traffic flow (May 1990)

\begin{tabular}{|l|l|l|}
\hline \multicolumn{1}{|c|}{$\begin{array}{c}\text { Traffic } \\
\text { characteristic }\end{array}$} & \multicolumn{1}{c|}{$\begin{array}{c}\text { Microscopic } \\
\text { level }\end{array}$} & \multicolumn{1}{c|}{$\begin{array}{c}\text { Macroscopic } \\
\text { level }\end{array}$} \\
\hline Flow & Time headways & Flow rates \\
\hline Speed & Individual speeds & Average speeds \\
\hline Density & Distance headways & Density rates \\
\hline
\end{tabular}

The other theoretical distinction of traffic flows is between homogeneous and inhomogeneous or heterogeneous traffic flows. Homogenous traffic flows are composed of vehicles with same characteristics, while the heterogeneous traffic stream consists of vehicles that have different speeds, sizes, operating characteristics, and vehicle spacing (see e.g. Katz 2009; Dadić, Kos 2007). In reality there are no homogenous traffic mixes, but the dividing line between homogeneous and heterogeneous traffic flows is not uniquely determined; it is possible to talk about heterogeneous traffic flow if the share of the dominant mode is less than certain percentage, more precisely around $85 \%$ during peak time (Katz 2009) or that there should be three types of vehicles using the same infrastructure, namely fast vehicles, slow vehicles and long vehicles (Kerner 2004). Another definition says that the heterogeneity of traffic flows is expressed in the share of commercial vehicles in the traffic flow, that is, with the share HGVs and buses (Dadić, Kos 2007).

It is possible to find many papers dealing with the heterogeneity of traffic flows in urban areas of de- veloping countries where mix of non-motorized and motorized modes exists (see e.g. Mizanur, Nakamura 2005; Lasmini et al. 2013), while there has not been a lot of published work on heterogeneity of traffic flows on motorways and its influence on traffic safety. Nevertheless, Ferrari dedicated his career to investigation of traffic flows on motorways, and in his recent works he emphasized the effect of HGVs on traffic flows on motorways; however, not on traffic safety (see Ferrari 2011, 2009). Martin (2002) on the other hand, has analysed traffic flows on 2000 kilometres of French motorways for the period of two years in order to determine the relation between traffic flows and crash occurrence, but with no specific attention to HGVs. Golob et al. (2004) presented a strong evidence between flow condition and the likelihood of traffic accidents by type of crash on motorways, while Marchesini and Weijermars (2010) explored the relationship between congestion and road safety on motorways from the theoretic point of view. Finally, Ramírez et al. (2009) investigated the impact of HGVs and traffic safety on Spanish interurban roads.

\section{Data}

It is well known that the reporting of road accidents in official statistics is incomplete and biased (Elvik et al. 2009), and even Brvar (2011) expressed doubts on the accuracy of Slovenian official statistics, but as there is no better publically available data on traffic accidents in Slovenia, we were forced to use the official data provided by Slovenian police.

Slovenia has a long tradition of traffic accidents data recording; first records on traffic accidents date back to early 1950s. The current data set is composed of two data bases; the first one including the information on the occurrence of the accident and the other one on the participants in these accidents. The two data bases are connected through the accident identification number and for purposes of this paper we created a unique data base on traffic accidents covering the period from 2001 to 2012 . We identified and removed 26 cases with mismatched identification number (same identification number for different cases). The year 2013 served for testing purposes.

In order to link the crash occurrence with the traffic flows it was essential to extract the data on traffic volume and traffic structure of traffic flows on Slovenian motorways from the annual publication of the Slovenian Roads Agency. This publication includes the data on traffic flows on all state roads.

In addition, Traffic Information Centre provides data from 587 automatic counters on Slovenian roads in real time over the web portal www.promet.si, but the system does not allow the retrieval of past data. In order to get the picture on how heterogeneity of traffic flows reflects on average speed of vehicles, average time between driving vehicles, and occupancy of the carriageway we recorded the data on traffic flows during March and April 2014. 


\section{Methods}

Descriptive statistics was used to get an overall picture on the trends and situation of traffic flows and traffic safety on Slovenian motorways.

Transport data, including traffic safety data, usually exhibit a seasonal pattern as well as a trend. The data on traffic safety on Slovenian motorways is not an exception. Therefore, it was reasonable to use seasonal decomposition to identify the seasonal components in the past data and use them in a forecasting model. Seasonal adjustment is done to simplify data so that they may be more easily interpreted by statistically unsophisticated users, without a significant loss of information (Bell, Hillmer 1984).

Because it was not possible to predict that the amplitude of seasonal and random effects was constant regardless of the trends, we annihilated the seasonality by using the multiplicative decomposition. In the multiplicative model, the original time series is expressed as follows:

$$
O_{t}=T_{t} \cdot S_{t} \cdot I_{t},
$$

where: $O_{t}$ denotes observed series; $T_{t}$ denotes trend (long term movement in the mean); $S_{t}$ denotes seasonal variation (short-term fluctuations); $I_{t}$ denotes irregular components.

The seasonally adjusted data then becomes:

$$
S A_{t}=\frac{O_{t}}{\hat{S}_{t}}=T_{t} \cdot I_{t},
$$

where: $S A_{t}$ denotes a seasonally adjusted series; $\hat{S}_{t}$ denotes the estimation of seasonal component.

AutoRegressive Integrated Moving Average (ARIMA) models are often used in forecasting traffic safety. ARIMA models were introduced by Box and Jenkins in 1960's and they include combined concepts of autoregressive model, a model of integration of time series and a model of a moving average and can be used on equally spaced univariate time series data (Box et al. 2013). Time series to which ARIMA model is fitted needs to be stationary. This means that a time series needs to have a constant mean and a constant variance over time.

Data on traffic accidents on Slovenian motorways show seasonality; thus, it was necessary to use a seasonal ARIMA method, which is denoted as $\operatorname{SARIMA}(p, d, q) \times(P, D, Q)_{S}$, where $(p, d, q)$ represent the non-seasonal, while $(P, D, Q)$ represent the seasonal part of the model. $p, d$ and $q$ (or $P, D, Q$ ) are nonnegative integers that refer to the order of the autoregressive, integrated, and moving average parts of the model. $S$ denotes the length of the seasonal periods. A $\operatorname{SARIMA}(p, d, q) \times(P, D, Q)_{S}$ model can be presented with the following formula:

$\Phi_{p}\left(B^{S}\right) \cdot \varphi_{p}(B) \cdot\left(1-B^{S}\right)^{D} \cdot y_{t}=\theta_{q}(B) \cdot \Theta_{q}\left(B^{S}\right) \cdot \varepsilon_{t}$,

where: $\Phi_{p}\left(B^{S}\right)$ denotes a seasonal autoregressive operator; $\varphi_{p}(B)$ denotes an autoregressive operator; $\theta_{q}(B)$ denotes a moving average operator; $\Theta_{q}\left(B^{S}\right)$ denotes a seasonal moving average operator; $B$ denotes a backshift operator; $\varepsilon_{t}$ is an error term.

A common approach to forecasting traffic safety is by the creation of Safety Performance Function (SPF). SPF is an equation used to predict the average number of crashes per year at a location as a function of exposure and in some cases roadway characteristics. The generalized form of models that used to forecast the number of road accidents takes the following form (see e.g. Eenink et al. 2008; Elvik et al. 2009):

$$
E(\lambda)=\alpha \cdot Q^{\beta} \cdot e^{\sum \gamma_{i} \cdot x_{i}},
$$

where estimated expected number of accidents; $E(\lambda)$ is a function of traffic volume; $Q$, and a set of risk factors; $x_{i}(i=1,2,3, \ldots, n)$. The effect of traffic volume on accidents is modelled in terms of an elasticity, that is, a power $\beta$, to which traffic volume is raised.

Traffic volumes [vehicles per day] and road lengths $[\mathrm{km}]$ are the most important explanatory variables in an Accident Prediction Models (APMs). The Austrian model goes one-step further and includes also the share of HGVs in traffic flows.

It would be good to make the selection of explanatory variables that are included in an APM based on theory; however, data availability is often a limiting factor. Thus, formula (4) often takes the following simplified form as suggested by Elvik et al. (2009):

$$
E(\lambda)=A A D T^{\beta},
$$

where: $A A D T$ stays for Average Annual Daily Traffic, which is a proxy for traffic volume. The presumption of this model is that accidents occur randomly, but at constant rate in regards to traffic activity.

\section{Results and Discussion}

\subsection{Basic Findings}

Around 245 kilometres of motorways were constructed in Slovenia in the period from 2001 to 2012. For this reason it was reasonable to convert data on transport volume to data on transport volume per kilometre of road. Transport volumes on Slovenian motorways have been constantly increasing in the analysed period with Average Annual Growth Rate (AAGR) of traffic work per kilometre of road reaching 3.2\% and Compound Annual Growth Rate (CAGR) 3.1\%. However, in the same period, the AAGR of HGVs traffic volume increased by 8.9 and the CAGR recorded $8.6 \%$. The structure of traffic flows has therefore changed significantly; while in 2001 the share of HGVs represented only 7.4\% of traffic volume on Slovenian motorways, it increased to an average of $13.1 \%$ by 2012 . Fig. 1 shows the shares of vehicles having speed limit $80 \mathrm{~km} / \mathrm{h}$ (that is, HGVs and buses) on Slovenian motorways and separately in the direction of corridor $\mathrm{V}$ over the analysed period. It is clearly visible that for several years, many sections of Slovenian motorways have accommodated more than $15 \%$ of such vehicles. This is especially the case on the sections of corridor V. 


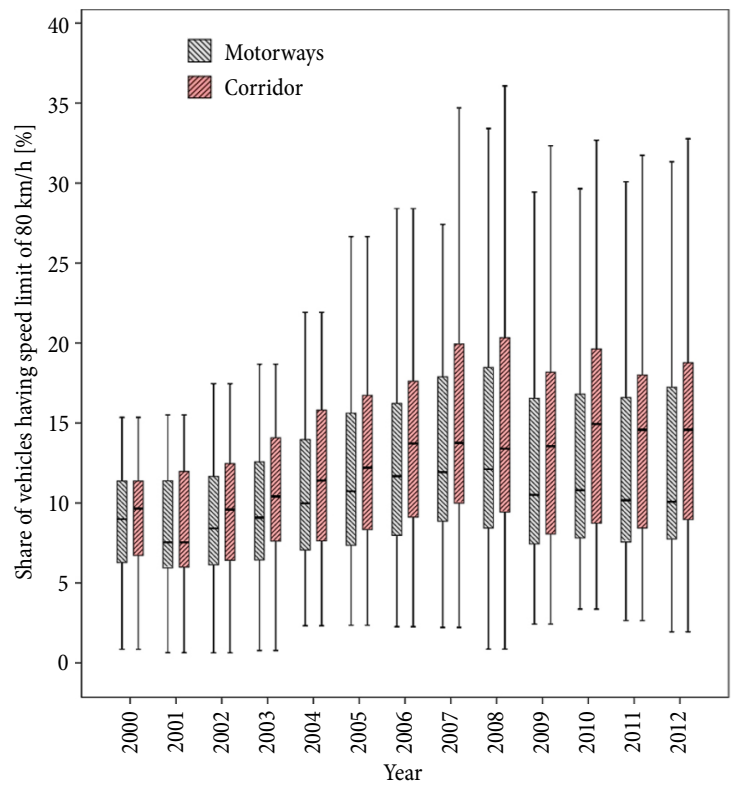

Fig. 1. Share of vehicles having speed limit $80 \mathrm{~km} / \mathrm{h}$ on Slovenian motorways

(source: authors, based on DRSzi (2013))

Note: Outliers (more than $3 / 2$ times of upper quartile and less than $3 / 2$ of lower quartile) have been removed from the chart

In the period from 2001 to 2012 a total of 26800 of traffic accidents occurred on Slovenian motorways, among which around $20 \%$ were injury accidents. The motorways accidents involved almost 48300 people, 249 of which have died, 725 were severely injured and more than 7500 suffered minor injuries.

There is an increasing trend in the number of accidents on Slovenian motorways over the analysed period (Fig. 2). In fact, the basic statistics on traffic safety on Slovenian motorways indicate the general decrease of safety, as AAGR and CAGR of number of traffic accidents on Slovenian motorways are positive and high, $6.6 \%$ and $5.0 \%$ respectively. Similar situation can be seen in injury accidents records; there is in general increasing trend with AAGR of 5.0\% and CAGR 3.7\%.

Proportion of the number of people killed on the motorways is growing; in 2001 the share of fatalities on motorways represented only $7 \%$ of all fatalities, while in 2012 this share was almost 14\%. However, it should be noted that back in 2001 motorways accommodated barely 21\% of all traffic flows in Slovenia, while in 2012 more than $44 \%$ of transport work flows was done on motorways, which is significantly above the European average (while accounting for more than one quarter of all kilometres driven, the European motorways contribute only to $8 \%$ of to the total number of road deaths (ETSC 2008)). With other words this means, the traffic volume on Slovenian motorways almost tripled in the analysed period.

In 2001 there were 9.03 fatalities per billion vehicle kilometres done on motorways and in 2012 this number dropped to 3.14 fatalities per billion of vehicle kilometres on motorways. So in the aspect of fatality risk it is possible to say that the safety on Slovenian motorways has improved significantly irrespectively of the changes in traffic structure. According to the fatality risk level, the motorways represent the safest roads in Slovenia, which is consistent with the theory (see e.g. ETSC 2008).

The greatest number of traffic accidents on Slovenian motorways occurs in summer time (July and August) and the most dangerous day seems to be Friday (18\% of all accidents) during afternoon and evening hours as can be seen in Fig. 3. Generally speaking there are two daily peak periods in which majority of accidents occur, that is, in the morning between 6 and $9 \mathrm{AM}$, and in the afternoon between 3 and 6 PM during week days.

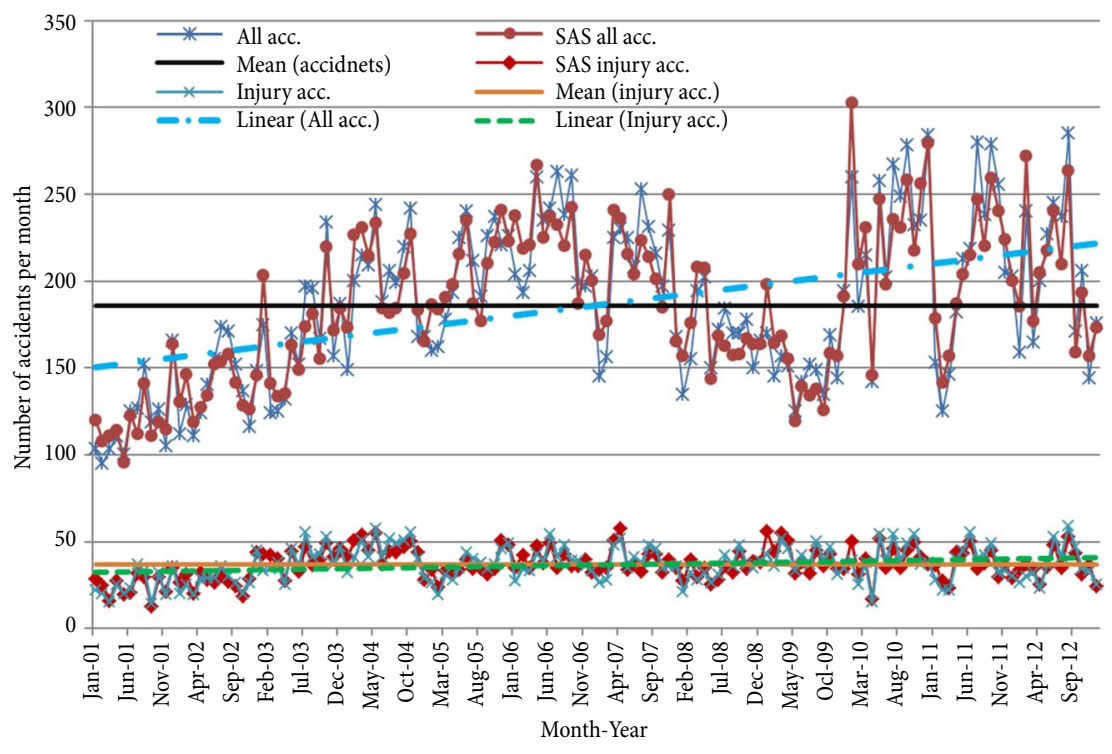

Fig. 2. Time series of all accidents and injury accidents on Slovenian motorways (source: authors, based on Policija (2015))

Note: SAS - Seasonal Adjusted Series 


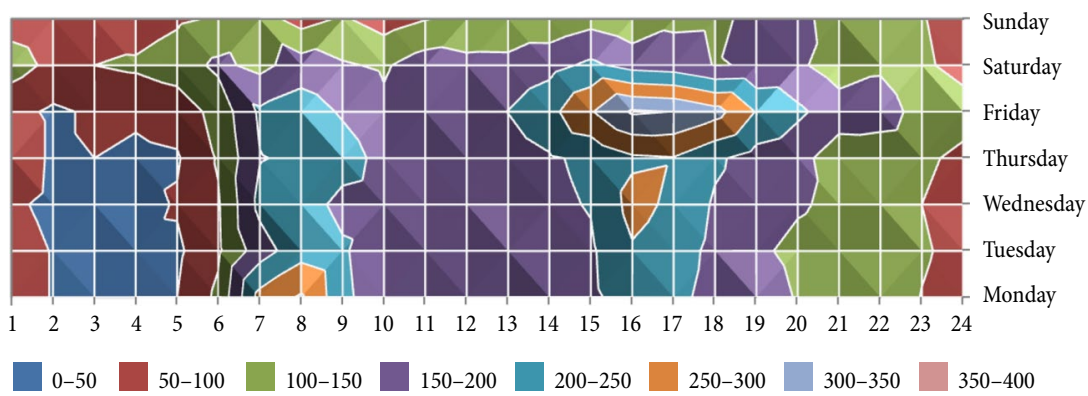

Fig. 3. Distribution of accidents by time of the day

(source: authors, based on Policija (2015))

The analysis of traffic situation during these periods indicates very common presence of heavy traffic, which is characterized by (in brackets are presented the results of traffic data recording in March and April 2014 which can serve as an indicator of traffic condition in certain periods of day, but cannot be generalized to past or future as the traffic flow and other conditions change):

- Higher density of vehicles on the fast lane than on regular lane (in $14.9 \%$ of measurements on motorways in general, and $25.7 \%$ on A1 motorway);

- Inadequate time heading (less than 2 seconds time heading in only $2.7 \%$ of measurements; however, in $18.2 \%$ of cases when there is more traffic on fast lane than on regular lane);

- High difference between the average speed on fast and regular line $(22.5 \mathrm{~km} / \mathrm{h}(22.0 \mathrm{~km} / \mathrm{h}$ on A1) when traffic density is higher on fast lane than on regular lane).

Around $70 \%$ of the accidents that took place on Slovenian motorways, occurred on the motorway A1, which corresponds to the ex pan-European corridor V. The motorways A1 takes on majority of the freight transit traffic over Slovenia and links several big Slovenian cities to Ljubljana; thus, it is not surprising that it records the highest AADT with higher shares of HGVs as seen in Fig. 1.

In the European Union a HGV is involved in 6\% of all accidents but in $16 \%$ of all fatal accidents - not necessarily meaning that the goods vehicle occupant is the victim of those accidents (EC 2013a, 2013b). In Slovenia these numbers are somewhat worse; in the analysed period the HGVs were involved in $27.5 \%$ of all accidents (while causing 14.5\% of all accidents (the inducer of the accident is not reported in $30.6 \%$ of cases)), and in $33.3 \%$ of fatal accidents (while causing $16.2 \%$ of such accidents). Regardless of the legislation (Uradni List 2006), that requires HGVs to use motorways wherever possible, still more than $75 \%$ of accidents involving HGVs occur on lower rank roads (Table 2).

As Tiwari (2000) stated, a heterogeneous traffic mix has an effect on traffic safety, especially traffic fatalities. And indeed, in Slovenia the traffic flow structure on motorways is becoming more and more heterogeneous while at the same time the trend line for the involvement of HGVs in traffic accidents and for the causation of accidents is increasing $(y=26.832 \cdot x+439.92$ and $y=$ $13 \cdot x+240$ respectively). The same direction is noticed

Table 2. The involvement of HGVs in traffic accidents on Slovenian motorways for the period 2001-2012 (source: authors, based on Policija (2015))

\begin{tabular}{|c|c|c|c|c|c|c|c|c|}
\hline \multirow{3}{*}{ Year } & \multicolumn{4}{|c|}{ All accidents } & \multicolumn{4}{|c|}{ Fatal accidents } \\
\hline & \multicolumn{2}{|c|}{ Involved in the accidents } & \multicolumn{2}{|c|}{ Caused the accidents } & \multicolumn{2}{|c|}{ Involved in the accidents } & \multicolumn{2}{|c|}{ Caused the accidents } \\
\hline & No. & $\%$ & No. & $\%$ & No. & $\%$ & No. & $\%$ \\
\hline 2001 & 306 & 21.4 & 195 & 13.6 & 0 & 0.0 & 0 & 0.0 \\
\hline 2002 & 392 & 23.5 & 226 & 13.5 & 8 & 44.4 & 3 & 16.7 \\
\hline 2003 & 491 & 24.4 & 282 & 14.0 & 5 & 25.0 & 3 & 15.0 \\
\hline 2004 & 641 & 26.6 & 352 & 14.6 & 8 & 53.3 & 3 & 20.0 \\
\hline 2005 & 701 & 28.4 & 331 & 13.4 & 9 & 37.5 & 4 & 16.7 \\
\hline 2006 & 775 & 28.7 & 405 & 15.0 & 6 & 27.3 & 1 & 4.5 \\
\hline 2007 & 831 & 33.5 & 357 & 14.4 & 12 & 52.2 & 5 & 21.7 \\
\hline 2008 & 648 & 32.0 & 321 & 15.8 & 2 & 22.2 & 1 & 11.1 \\
\hline 2009 & 447 & 24.4 & 256 & 14.0 & 6 & 40.0 & 4 & 26.7 \\
\hline 2010 & 761 & 27.1 & 413 & 14.7 & 4 & 30.8 & 2 & 15.4 \\
\hline 2011 & 709 & 28.4 & 389 & 15.6 & 6 & 46.2 & 5 & 38.5 \\
\hline 2012 & 670 & 27.3 & 367 & 14.9 & 2 & 11.8 & 2 & 11.8 \\
\hline Total & 7372 & 27.5 & 3894 & 14.5 & 68 & 33.3 & 33 & 16.2 \\
\hline
\end{tabular}


for the causation of fatal accidents $(y=0.1154 \cdot x+2)$ while a slight decrease is observed in the involvement of HGVs in fatal accidents $(y=-0.0979 \cdot x+6.303)$.

In 2012, at least one HGV was involved in 7372 accidents on Slovenian motorways, that is, in $27.5 \%$ of all accidents, and this share is even larger on A1, on which at least one HGV participated in $31.1 \%$ of accidents.

\subsection{Forecasting the Number of Traffic Accidents on Slovenian Motorways}

As seen in Fig. 2, the time series on the number of traffic accidents on Slovenian motorways has a positive trend (0.4985), and is thus not stationary. The stationarity is generally best achieved by transforming the original series to a stationary time series either by differencing or by using log transformation. In fact, after applying the first difference, almost perfectly stationary time series with a slight negative trend (-0.0275) was achieved.

According to AutoCorrelation Function (ACF) and Partial AutoCorrelation Function (PACF), we achieved best fitting with the $\operatorname{SARIMA}(0,1,1)(0,1,1)_{12}$ model (Table 3). Graph of residuals as well Durbin-Watson (2.09) test prove that there is no autocorrelation among residuals in the selected model.

The available data allows the test of the model on the 2013 traffic accidents data on Slovenian motorways; the reported number of traffic accidents in 2013 was 2294 while the model forecasted 2284 accidents. The forecast for longer period is presented in the Table 4 .

Accidents are the outcome of mix of various factors; however, increasing traffic volumes are usually related to increasing number of accidents:

$$
E(\lambda)=A A D T^{0.7577} \text {. }
$$

As the particular interest of this paper is given to the influence of the HGVs on traffic safety on Slovenian motorways we included the share of HGV (\%HGV) into the model:

Table 3. SARIMA model parameters for the number of traffic accidents on Slovenian motorways

\begin{tabular}{|c|c|c|c|c|c|}
\hline & & Estimate & SE & $t$ & Sig. \\
\hline \multicolumn{2}{|c|}{ Difference } & 1 & & & \\
\hline MA & Lag 1 & 0.608 & 0.074 & 8.211 & 0.000 \\
\hline \multicolumn{2}{|c|}{ Seasonal Difference } & 1 & & & \\
\hline MA, Seasonal & Lag 1 & 0.938 & 0.292 & 3.217 & 0.002 \\
\hline
\end{tabular}

Table 4. The forecasted number of accidents on Slovenian motorways for the period 2014-2017

\begin{tabular}{|c|c|}
\hline Year & $\begin{array}{c}\text { Forecasted number of accidents } \\
\text { on Slovenian motorways }\end{array}$ \\
\hline 2014 & 2443 \\
\hline 2015 & 2601 \\
\hline 2016 & 2760 \\
\hline 2017 & 2918 \\
\hline
\end{tabular}

$$
E(\lambda)=A A D T^{0.8221} \cdot \% H G V^{0.3110} .
$$

The length of Slovenian motorways changed significantly in the analysed period; thus, it was not reasonable to include the motorways length into the model as it yields unexpected results at the first sight. In fact, with the increasing length the number of accidents drops which is probably the consequence of longer continuity of segments and less dangerous points. Further analysis with GIS data on traffic accidents would probably clarify this assumption.

\section{Conclusions}

It is often stressed that Slovenia is a country with extremely good geo-strategic position. This was a challenge and opportunity two decades ago, but in the future it might represent a huge problem. The Slovenian motorways system is now completed on the main directions, which correspond with the directions of formal corridor $\mathrm{V}$ and $\mathrm{X}$, but the railways system is still very deficient. This means that the increasing traffic flows need to be accommodated by motorways and that consequently the structure of traffic flows is changing especially on the direction of corridor $\mathrm{V}$, making the traffic stream heterogeneous and thus more dangerous.

With the increase of heterogeneity of traffic flow, the travelling conditions deteriorate. By theory in developed world this is due to the larger size and lower driving capacities of commercial vehicles sharing the same roads with personal cars.

The obtained models suggest that it is possible to expect the increased number of traffic accidents on Slovenian motorways. Now, with the Slovenian motorways system being more or less completed the increasing volume of traffic and the changing structure of traffic flows will have negative impact on traffic safety as suggested by the developed models.

As determined by the research, the involvement of HGVs in traffic accidents is much more present on Slovenian roads than the European average is. Future research will be thus focused on defining the traffic safety models for the A1 motorways segment, that is the segment which corresponds to the corridor $\mathrm{V}$ and is therefore the most intensively used by HGVs.

\section{References}

Bell, W. R.; Hillmer, S. C. 1984. Issues Involved with the Seasonal Adjustment of Economic Time Series. SRD Research Report No: CENSUS/SRD/RR-84/09. Bureau of the Census, Washington, D.C. 100 p. Available from Internet: https:// www.census.gov/srd/papers/pdf/rr84-09.pdf

Box, G. E. P.; Jenkins, G. M.; Reinsel, G. C. 2013. Time Series Analysis: Forecasting and Control. John Wiley \& Sons, Inc. 755 p. http://dx.doi.org/10.1002/9781118619193

Brvar, B. 2011. Uradna in dejanska statistika mrtvih v prometu, Delo, 02.08.2011. Available from Internet: http://www.delo. si/mnenja/gostujoce-pero/uradna-in-dejanska-statistikamrtvih-v-prometu.html (in Slovenian).

Cowie, J. 2009. The Economics of Transport: a Theoretical and Applied Perspective. 1st edition. Routledge. 400 p. 
Dadić, I.; Kos, G. 2007. Teorija i organizacija prometnih tokova. Fakultet prometnih znanosti, Sveučilište u Zagrebu. 169 c. (in Croatian).

DRSzi. 2013. Podatki o prometu (2001-2012). Direkcija Respublike Slovenije za infrastrukturo (DRSzi). Available from Internet: http://www.di.gov.si/si/delovna_podrocja_in_podatki/ceste_in_promet/podatki_o_prometu (in Slovenian).

EC. 2013a. Road Safety Vademecum - Road Safety Trends, Statistics and Challenges in the EU 2011-2012. European Commission, DG for Mobility and Transport, Unit C.4 - Road Safety. 17 p. Available from Internet: http://ec.europa.eu/ transport/road_safety/pdf/vademecum_2013.pdf

EC. 2013b. Towards a Strategy on Serious Road Traffic Injuries - Frequently Asked Questions. European Commission, Press Release Database. 5 p. Available from Internet: http:// europa.eu/rapid/press-release_MEMO-13-232_en.htm

Eenink, R.; Reurings, M.; Elvik, R.; Cardoso, J.; Wichert, S.; Stefan, C. 2008. Accident Prediction Models and Road Safety Impact Assessment: Recommendations for Using These Tools. Contract N. 506184. RIPCORD-ISEREST Deliverable D2. 20 p. Available from Internet: http://ec.europa.eu/transport/roadsafety_library/publications/ripcord_d02_road_ safety_impact_assessment.pdf

Elvik, R.; Høye, A.; Vaa, T.; Sørensen, M. 2009. The Handbook of Road Safety Measures. 2nd edition. Emerald Group Publishing Limited. $1124 \mathrm{p}$.

ETSC. 2008. Fate of EU Motorway Safety in Hands of MEPs. European Transport Safety Council (ETSC). 2 p. Available from Internet: http://archive.etsc.eu/document. php?articleId $=443$

Ferrari, P. 2011. The dynamics of the competition between cars and trucks on motorways, Transportation Research Part C: Emerging Technologies 19(4): 579-592. http://dx.doi.org/10.1016/j.trc.2010.09.012

Ferrari, P. 2009. The effect of the competition between cars and trucks on the evolution of the motorway transport system, Transportation Research Part C: Emerging Technologies 17(6): 558-570. http://dx.doi.org/10.1016/j.trc.2009.05.002

Golob, T. F.; Recker, W. W.; Alvarez, V. M. 2004. Freeway safety as a function of traffic flow, Accident Analysis \& Prevention 36(6): 933-946. http://dx.doi.org/10.1016/j.aap.2003.09.006

Hoogendoorn, S.; Knoop, V. 2013. Traffic flow theory and modelling, in B. Van Wee, J. A. Annema, D. Banister (Eds.). The Transport System and Transport Policy: an Introduction. Cheltenham, UK: Edward Elgar Publishing, 125-159.

Katz, D. 2009. Heterogeneous Traffic Mixes. CEE 6603 - Term Paper. 11 p. Available from Internet: http://www.donaldkatz.com/CEE\%206603\%20-\%20Term\%20Paper\%20-\%20 Heterogeneous\%20Traffic.pdf

Kerner, B. S. 2004. The Physics of Traffic: Empirical Freeway Pattern Features, Engineering Applications, and Theory. Springer Berlin Heidelberg. 682 p. http://dx.doi.org/10.1007/978-3-540-40986-1

Lasmini, A.; Pel, A. J.; Verhaeghe, R.; Van Arem, B. 2013. Empirical analysis of heterogeneous traffic flow, Proceedings of the Eastern Asia Society for Transportation Studies 9: 1-15.

Marchesini, P.; Weijermars, W. 2010. The Relationship between Road Safety and Congestion on Motorways: a Literature Review of Potential Effects. Report No R-2010-12. SWOV Institute for Road Safety Research, The Netherlands. 30 p. Available from Internet: http://www.swov.nl/ rapport/R-2010-12.pdf
Martin, J.-L. 2002. Relationship between crash rate and hourly traffic flow on interurban motorways, Accident Analysis \& Prevention 34(5): 619-629.

http://dx.doi.org/10.1016/S0001-4575(01)00061-6

May, A. D. 1990. Traffic Flow Fundamentals. Prentice Hall. 464 p.

Mizanur, R.; Nakamura, F. 2005. A study on passing - overtaking characteristics and level of service of heterogeneous traffic flow, Journal of the Eastern Asia Society for Transportation Studies 6: 1471-1483. http://doi.org/10.11175/easts.6.1471

Ortúzar, J. D.; Willumsen, L. G. 2011. Modelling Transport. 4 th edition. Wiley. $607 \mathrm{p}$.

Papageorgiou, M. 2003. Traffic control, in R. W. Hall. (Ed.). Handbook of Transportation Science, 243-278.

Policija. 2015. Prometna varnost: statistika. Ministrstvo za notranje zadeve. Policija. Available from Internet: http:// www.policija.si/index.php/statistika/prometna-varnost (in Slovenian).

Ramírez, B. A.; Izquierdo, F. A.; Fernández, C. G.; Méndez, A. G. 2009. The influence of heavy goods vehicle traffic on accidents on different types of Spanish interurban roads, Accident Analysis \& Prevention 41(1): 15-24. http://dx.doi.org/10.1016/j.aap.2008.07.016

Tiwari, G. 2000. Traffic flow and safety: need for new models for heterogeneous traffic, in D. Mohan, G. Tiwari (Eds.). Injury Prevention and Control, 73-91.

Uradni List. 2006. Pravilnik o omejitvi uporabe državnih cest za promet tovornih vozil, katerih največja dovoljena masa presega 7,5 ton, Uradni List - Official Gazette of the Republic of Slovenia, 102/2006: 10423-10424. (in Slovenian).

WHO. 2013. Global Status Report on Road Safety 2013: Supporting a Decade of Action. World Health Organization (WHO). 318 p. Available from Internet: http://www.who.int/ violence_injury_prevention/road_safety_status/2013/en 